Original Research Paper

\title{
Detection of Commercial Fraud in Processed Meat Products Using Rapid Techniques
}

\author{
${ }^{1}$ Ali M. Ahmed, ${ }^{2}$ Takwa H. Ismail, ${ }^{3}$ Reham R. Abouelmaatti, ${ }^{2}$ Rehab E.M. Gaafar and ${ }^{4}$ Wael M.K. Elfeil \\ ${ }^{1}$ Department of Food Hygiene, Faculty of Veterinary Medicine, Suez Canal University, Ismailia, Egypt \\ ${ }^{2}$ Department of Food Hygiene, Animal Health Research Institute, Ismailia, Egypt \\ ${ }^{3}$ Key Laboratory of Animal Epidemiology and Zoonosis, Sharkia Vet. Directorate, \\ General Org. Vet. Services, Ministry of Agriculture, Egypt \\ ${ }^{4}$ Avian and Rabbit Medicine, Faculty of Veterinary Medicine, Suez Canal University, Ismailia, Egypt
}

\author{
Article history \\ Received: 14-10-2019 \\ Revised: 31-01-2020 \\ Accepted: 03-06-2020 \\ Corresponding Author: \\ Rehab E.M. Gaafar \\ Department of Food Hygiene, \\ Animal Health Research \\ Institute, Ismailia, Egypt \\ Email: elsayed.scu@gmail.com
}

\begin{abstract}
Meat adulteration with different species has become a considerable problem worldwide. It means that meat products contain undeclared meat species; so, the meat ingredients are not consistent with the label. It has direct impact on public health, religious faith, fair-trades and food safety standers. This study focused on species adulteration detection in meat products by applying accurate, slandered and fast techniques. Polymerase Chain Reaction (PCR) technique and Raw Meat FlowThrough ${ }^{\mathrm{TM}}$ Test were performed as fast techniques. Thirty samples of beef meat products (10 each of hawawshi, sausage and burger) were subjected to analysis by PCR technique using specific primers sets for equine, chicken and pig species on samples' Deoxyribonucleic Acid (DNA). The adulteration rates with equine were 10\%, 10\% and 30\% in hawawshi, sausage and beef burger samples, respectively. The adulteration rates with chicken were $80 \%, 50 \%$ and $100 \%$ in hawawshi, sausages and beef burger samples, respectively. While none of the examined samples was contaminated with pork. Results showed that $80 \%$ of all examined samples contained undeclared meat species. Out of the adulterated samples examined by PCR technique, eight samples were reanalyzed by the onsite Raw Meat FlowThrough $^{\mathrm{TM}}$ Test which had taken only about 12 minutes to be performed. It was an on-site test for qualitative determination of species by visual inspection. The results confirmed those obtained by PCR technique by $100 \%$ in case of detection of poultry species. While in case of detection of adulteration by equine species, the FlowThrough ${ }^{\mathrm{TM}}$ Test gave negative results which indicated that it had the ability to detect horse specie only but could not detect other equine species as donkey and mule. This study suggests that these methods of detection can be applied by quality control laboratories and inspection services for fast and rapid determination of adulteration with poultry products in different meat products, but the FlowThrough ${ }^{\mathrm{TM}}$ Test is horse specific inside the equine species and this could be limitation to the test needs to improve it or beneficial points to differentiate between horse and donkey meat adulation combining with other methods.
\end{abstract}

Keywords: Meat Adulteration, Horse Meat, Beef, Donkey Meat, PCR, Onset Assay

\section{Introduction}

Meat species adulteration is a problem which violates food labeling laws, constitutes economic fraud and raises ethical, religious and food safety concern. It may occur by substitution of low-priced or even banned meat species for that high-priced one. Many meat products nowadays may contain several species in different proportions mixed together and undetectable by the naked eye or by eating (Zarringhabaie et al., 2011). The Islamic law prohibits Muslims from eating pork and ingredients derived from them, in addition to horse and donkey meat which is Makrooh for Muslims, so the presence of equine meat or pork in products is 
unacceptable by the Muslim consumers, even though contamination is unintentional and incidental level. Additionally, these animals could be obtained without any offered prices and hence there is a significant chance of mixing them in halal foods (Rahman et al., 2014). In some cases, misleading labels may be harmful for individuals who have food allergies and the consumption of meat and meat products may create health concerns (Wang et al., 2004). By regard to the above facts and the high demand for more transparency in food industry, detection of meat species by fast and accurate methods should routinely be carried out for the quality control as well as a public task to secure the food safety all over the world (Unajak et al., 2011). Most analytical methods utilized to date for meat authentication have relied on the detection of species-specific proteins or DNA (Ballin et al., 2009). The Polymerase Chain Reaction (PCR) method deserves special attention because it is characterized by high sensitivity and specificity as well as relatively short period of time necessary to perform the analysis (Yosef et al., 2014; Ilhak and Güran, 2014). While the Raw Meat FlowThrough ${ }^{\mathrm{TM}}$ Test (RMFT) was used for on-site qualitative detection of species adulteration in uncooked meat products with a limit of detection of $1 \%$. It was simple and quick to be performed and require no additional equipment.

\section{Materials and Methods}

\section{Conventional Polymerase Chain Reaction (PCR) Technique}

Collection of Samples: A total of 30 beef meat products (10 each of hawawshi "its consist of breed and beef meat inside", sausage "contain beef meat" and burger "beef meat") were randomly collected from local and high different fast food restaurants and supermarkets located in Ismailia city.

DNA Extraction: According to the manufacturer's instruction provided by The QIAamp DNA Mini Kit (Catalogue no.51304, Qiagen, Germany).).

\section{PCR Amplification}

Oligonucleotide primers (Midland Certified Reagent Company oilgos, USA): Their Specific species, sequences, amplified products and references are shown in Table 1.

PCR Master Mix: Prepared according to Emerald Amp GT PCR master mix Takara, Code No. RR310A, Takara, Japan).

The cycling conditions: The temperature and time conditions of the primers during PCR are shown in Table 2. To visualize the PCR products, we used gel pilot 100 $\mathrm{pb}$ ladder (Qiagen, USA) according to manufacture instructions and run on agarose gel for electrophoresis (Sambrook et al., 1989).

\section{Raw Meat FlowThrough ${ }^{T M}$ Test (RMFT)}

Catalogue Numbers: Horse (Orange) R6051, Poultry (Blue) R6058. Components: Each single test contained 1 piece of Push-cap tube with yellow Extraction Solution, Sample scoop (0.5cc), Separation disc, Self-measuring pipette, Screw-cap tube containing Diluent Liquid, RMFT unit in foil pouch with desiccant, Cotton bud and Pink "highlighted black" Colour Reagent in colored cap tube.

Preparation of the samples: eight samples (2 hawawshi, 2 sausage and 4 burgers) were chosen from the previously proved adulterated samples by chicken and equine species to be retested with the Meat FlowThrough $^{\mathrm{TM}}$ Test. Chicken and horse meats were used as positive control samples. The chosen samples were finely minced to a smooth, homogenous paste.

Procedure: It had taken typically 12 minutes to be performed. Species-specific proteins were extracted from a homogenous sample with the yellow solution. The extract was then diluted and added to the test unit so that the proteins bound to a Test spot $(\mathrm{T})$ on the left-hand side of the test area (Fig. 1). Binding of these proteins was indicated after the addition of a Colour Reagent, which formed a pink spot at ' $\mathrm{T}$ '. A pink Control (C) spot also had appeared on the right-hand side of the test area to indicate the test had worked properly.

Table 1: Oligonucleotide primers

\begin{tabular}{llll}
\hline Specific species & Primer Sequence 5'-3' & Amplified product & Reference \\
\hline Donkey and Horse & TTCTGCTCTGGGTGTGCTACTT & $221 \mathrm{bp}$ & (Doosti et al., 2014) \\
Chicken & CTACTTCAGCCAGATCAGGC & $266 \mathrm{bp}$ & \\
Pig & GGGACACCCTCCCCCTTAATGACA & & \\
& CTACATAAGAATATCACCCAC & $290 \mathrm{bp}$ & (Tasara et al., 2005) \\
\hline
\end{tabular}

Table 2: PCR cycling conditions

\begin{tabular}{|c|c|c|c|c|c|c|}
\hline Gene & $\begin{array}{l}\text { Primary } \\
\text { denaturation }\end{array}$ & $\begin{array}{l}\text { Secondary } \\
\text { denaturation }\end{array}$ & Annealing & Extension & $\begin{array}{l}\text { No. of } \\
\text { cycles }\end{array}$ & $\begin{array}{l}\text { Final } \\
\text { extension }\end{array}$ \\
\hline Donkey and horse & $94^{\circ} \mathrm{C} 5 \mathrm{~min}$ & $94^{\circ} \mathrm{C} 30 \mathrm{sec}$. & $52^{\circ} \mathrm{C} 30 \mathrm{sec}$ & $72^{\circ} \mathrm{C} 30 \mathrm{sec}$. & 35 & $72^{\circ} \mathrm{C} 7 \mathrm{~min}$ \\
\hline Chicken & $94^{\circ} \mathrm{C} 5 \mathrm{~min}$. & $94^{\circ} \mathrm{C} 30 \mathrm{sec}$. & $60^{\circ} \mathrm{C} 30 \mathrm{sec}$. & $72^{\circ} \mathrm{C} 30 \mathrm{sec}$. & 35 & $72^{\circ} \mathrm{C} 7 \mathrm{~min}$ \\
\hline Pig & $94^{\circ} \mathrm{C} 5 \mathrm{~min}$. & $94^{\circ} \mathrm{C} 30 \mathrm{sec}$. & $52^{\circ} \mathrm{C} 40 \mathrm{sec}$. & $72^{\circ} \mathrm{C} 40 \mathrm{sec}$ & 35 & $72^{\circ} \mathrm{C} 10 \mathrm{~min}$. \\
\hline
\end{tabular}




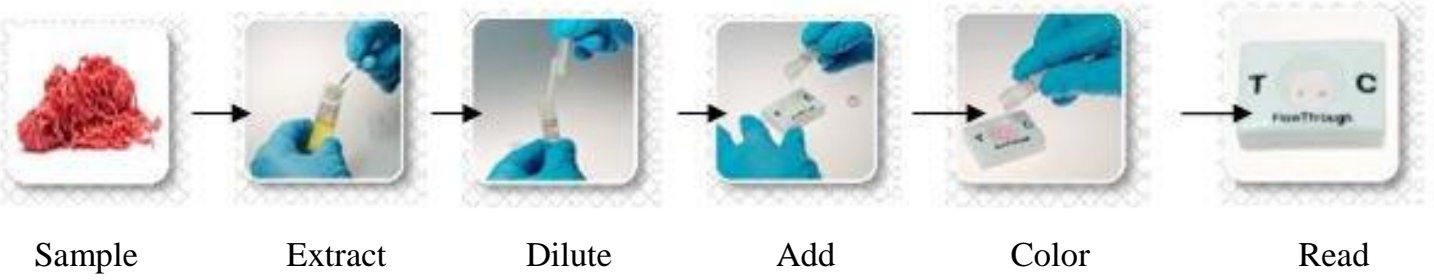

Fig. 1: Raw Meat FlowThroughTM Test (RMFT) using steps

\section{Results and Discussion}

Processed meat products are susceptible targets for fraudulent labeling due to the economic profit that results from selling cheaper meats as partial or total replacements for high-value ones (Mafra et al., 2008). PCR analysis of species-specific mitochondrial DNA sequences is the most common method currently used for identification of meat species in meat (Ahmed et al., 2007; Rahman et al., 2014). PCR identification of species gives a series of advantages due to its present in thousands of copies per cell (Montiel-Sosa et al., 2000). Using of target DNA was successfully identified for each species tested as illustrated in Fig. 2 which showed the electrophoretic gel photos of the examined samples. Amplification was not affected by additives or processing, also the presence of DNA from the other species did not affect the detection of target DNA's, similar observation was concluded by (Kesmen et al., 2007). According to negative controls, no environmental contamination was detected. The results presented in Table 3 showed that the adulteration rates for hawawshi, sausages and beef burger with equine were $10 \%, 10 \%$ and $30 \%$ respectively, while their adulteration rates with chicken meat were $80 \%, 50 \%$ and $100 \%$, respectively. While none of the samples were adulterated with pig. The general incidence of adulteration of hawawshi, sausages and beef burger samples were $80 \%, 60 \%$ and $100 \%$, respectively with $80 \%$ of total examined samples were contained undeclared species as presented in Table 4. The founded results were higher than that obtained by (Hussien, 2011) who found the adulteration rates of hawawshi with chicken and donkey were $65 \%$ and $5 \%$ respectively. (Zahran and Hagag, 2015) indicated that $5 \%$ of examined sausage samples were contaminated with donkey meat, Also (Ahmed et al., 2011) showed that the adulteration rate of sausage with donkey was $8 \%$ and for beef burger with chicken and donkey were $69 \%$ and $7.7 \%$, respectively. Additionally, (Doosti et al., 2014) found that the adulteration rates of sausage and burger samples with donkey were $7.35 \%$ and $3.63 \%$, respectively. Also the results were more than that obtained by (Cawthorn et al., 2013) who reported that chicken was identified as an undeclared species in $39 \%$ and $40 \%$ of sausage and burger samples respectively. In addition to (Ghovvati et al., 2009) who reported that $40 \%$ of sausages samples were contaminated with poultry residuals. Additionally, (Mehdizadeh et al., 2014) showed that $94.4 \%$ of burger samples were contained undeclared chicken meat. \% indicated that $23.3 \%$ of samples were containing poultry meat and $2 \%$ of the samples generated equine fragment. On the other hand, the results were lower than that found by (Ahmed et al., 2011) who showed that the adulteration rates for sausages with pork and chicken were $41.7 \%$ and $66.7 \%$, respectively and the adulteration rates for beef burger with pork was $23 \%$. In addition to (Hussien, 2011) who found that the adulteration rate of sausage with chicken and pork were $70 \%$ and $45 \%$ respectively and reported that $50 \%$ of the examined hawawshi samples were contaminated with pork. Also the results were lower than found by (Joseph et al., 2006) who examined sausage samples and detected adulteration rate of $44 \%$ with pork. Also (Cawthorn et al., 2013) reported that pork was detected in $52 \%$ of the examined sausage samples and in 30\% of the examined beef burger samples. (Doosti et al., 2014) who reported that the adulteration rate with pork $1.81 \%$. But the results were agreed with (Hussien, 2011) who found that $10 \%$ of sausage samples were adulterated with donkey. Also the results were agreed with (Ghovvati et al., 2009; Doosti et al., 2014) who found that no sausage samples contained pork. Certainty of no beef meat products adulterated with pork was a good result as base of Muslims consumer safety warranty. The absence of pork adulteration as appeared in this study maybe associated with the Egyptian government new regulation to restrict and prevent pig rearing in Egypt since the swine influenza crisis on 2015-2016 and this may be explain why there is no pork adulteration right now and previously was with high percentage(Gaafar, 2017). The presence of multiple undeclared species in meat products are likely indications of intentional adulteration. Low priced or lower valued meat species may substitute higher valued ones (Zahran and Hagag, 2015). These meat products which contain less desirable species may cause health risk and species identification is becoming a common and important practice (Ali, 2011; Mahmod, 2008). Apart from the potential, an explanation for the high incidence of chicken undeclared species in the 
examined products could have been due to the lower price of chicken meat compared with beef. Chicken waste products, called trimmings such as fat connective tissue, cartilage and even pieces of bone may be mixed with meat and used as adulterants. These waste products have lower nutritional value rather than meat (Gaafar, 2017). In addition to increased rate of adulteration with chicken mean, this may be associated with the poultry pathogen epidemiological situation in Egypt in the recent five years and emerging of new pathogens or new variant from old endemic pathogens which associated with increase mortalities in poultry farms either due to viral pathogen like infectious bronchitis, avian influenza, Newcastle virus (Ayoub et al., 2019; Diab et al., 2019; Elhady et al., 2018; Fawzy et al., 2019; Sedeik et al., 2018; Sultan et al., 2019a; 2019b) or bacterial pathogen like Pasteurella, E. coli and clostridium or parasite like coccidia (Eid et al., 2016; 2019; Elfeil et al., 2012; Enany et al., 2018)., They may also be contaminated with food borne pathogens. Therefore, the probable presence of these pathogens due to insufficient cooking temperature in final products poses a potential health risk for consumers (Mehdizadeh et al., 2014). The popularity of poultry meat also increases the chance of mixing mechanically deboned poultry tissue with ground or comminuted mammalian products The regulations to protect the public health against adulteration strictly prohibit the inedible and lower quality meat either to be directly launched or to be processed in the food chain (Bowling et al., 2007). One possible reason of high adulteration rate occurred in processed meat products is accidental contamination resulting from improper handling or processing (Hsieh et al., 1996; Ayaz et al., 2006).

Some testing characteristics like becoming fast, accurate, sensitive, selective, user friendly are commonly requested for acceptance of a new analytical method (Ilhak and Arslan, 2007). By application of the raw meat Flowthrough ${ }^{\mathrm{TM}}$ test (RMFT) which was used for on-site detection of raw meat species adulteration, the results were appeared within $12 \mathrm{~min}$. It was found that RMFT is a qualitative analysis, sensitive, highly specific (no known 'false' positives) and easy to use. Their reliable results provide evidence for effective decision making. The principle of this test depends on utilizing highly purified antibodies to detect species-specific animal serum protein (albumin), which is found at high levels in raw meat.

Table 3: Incidence of adulteration of Examined meat product samples by different species of meat detected by conventional PCR technique

\begin{tabular}{|c|c|c|c|c|c|c|c|c|}
\hline & \multicolumn{6}{|c|}{ Examined meat products } & & \\
\hline & \multicolumn{2}{|c|}{ Hawawshi } & \multicolumn{2}{|c|}{ Sausage } & \multicolumn{2}{|c|}{ Beef Burger } & \multicolumn{2}{|c|}{ Total } \\
\hline & No. & $\%$ & No. & $\%$ & No. & $\%$ & No. & $\%$ \\
\hline Equine & 1 & 10 & 1 & 10 & 3 & 30 & 5 & 16.6 \\
\hline Chicken & 8 & 80 & 5 & 50 & 10 & 100 & 23 & 76.6 \\
\hline pig & 0 & 0 & 0 & 0 & 0 & 0 & 0 & 0.0 \\
\hline
\end{tabular}

Table 4: General incidence of adulteration of different examined meat product samples detected by conventional PCR technique

\begin{tabular}{lllll} 
& Examined meat products & & \\
& Hawawshi & Sausage & Beef Burger & Total \\
\hline No. of examined samples & 10 & 10 & 10 & 30 \\
No. of adulterated samples & 8 & 6 & 10 & 24 \\
$\%$ of adulteration & 80 & 60 & 100 & 80 \\
\hline
\end{tabular}

Table 5: Incidence of adulteration of meat product samples by equine and chicken species detected by raw meat FlowThrough ${ }^{\mathrm{TM}}$ test

\begin{tabular}{llllll}
\hline & $\begin{array}{l}\text { Sample } \\
\text { ID code }\end{array}$ & $\begin{array}{l}\text { Description of the } \\
\text { sample }\end{array}$ & $\begin{array}{l}\text { Test } \\
\text { spot }\end{array}$ & $\begin{array}{l}\text { Control } \\
\text { spot }\end{array}$ & $\begin{array}{l}\text { Detected/not } \\
\text { detected }\end{array}$ \\
\hline Chicken species detection & C1 & Control chicken meat & $\checkmark$ & $\checkmark$ & $\begin{array}{l}\text { Detected } \\
\text { Detected }\end{array}$ \\
& 1 & Hawawshi sample & $\checkmark$ & $\checkmark$ & Detected \\
Equine species detection & 2 & Sausage sample & $\checkmark$ & $\checkmark$ & Detected \\
& 3 & Burger sample & $\checkmark$ & $\checkmark$ & Detected \\
& 4 & Burger sample & $\checkmark$ & $\checkmark$ & Detected \\
& C2 & Control horse meat & $\checkmark$ & $\checkmark$ & Not detected \\
& 5 & Hawawshi sample & --- & $\checkmark$ & Not detected \\
& 7 & Sausage sample & --- & $\checkmark$ & Not detected \\
& 8 & Burger sample & --- & $\checkmark$ & Not detected \\
\hline
\end{tabular}




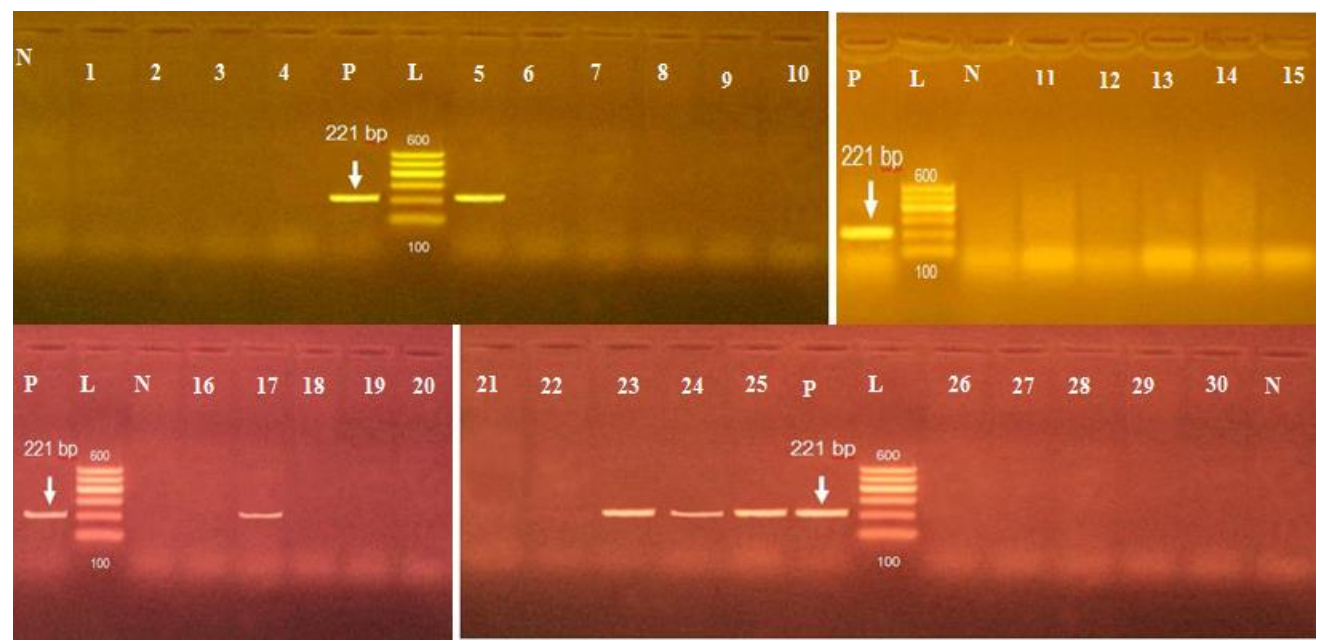

(a)

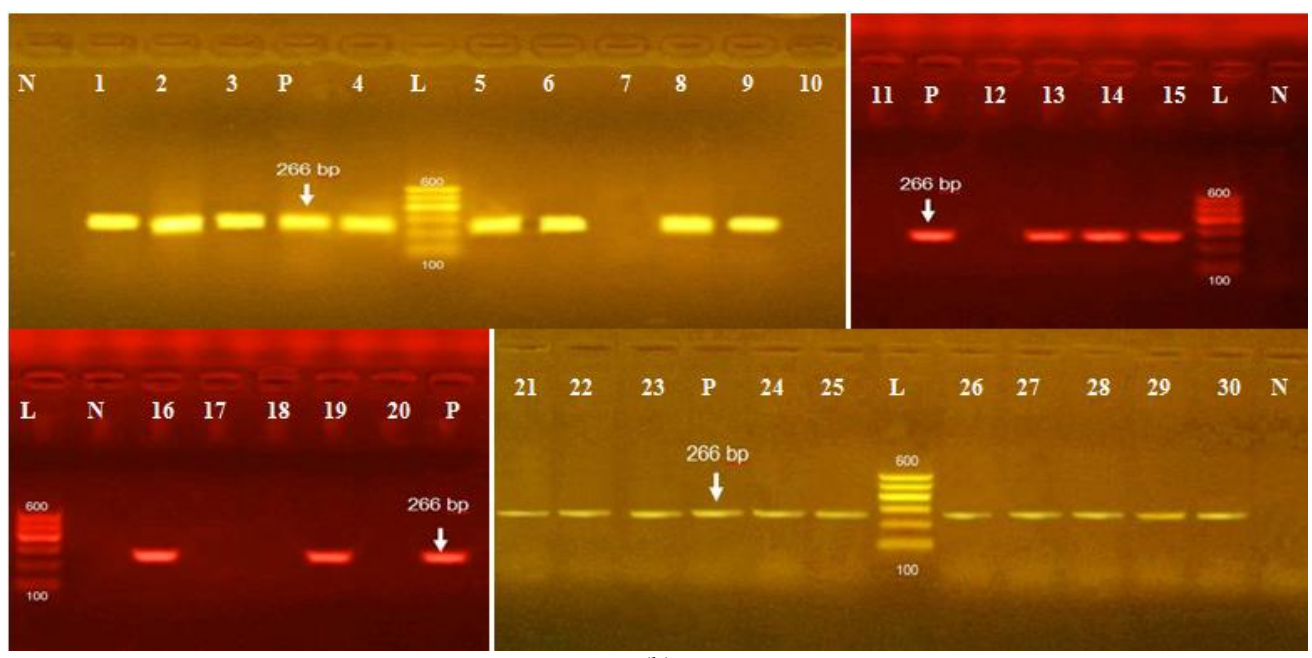

(b)

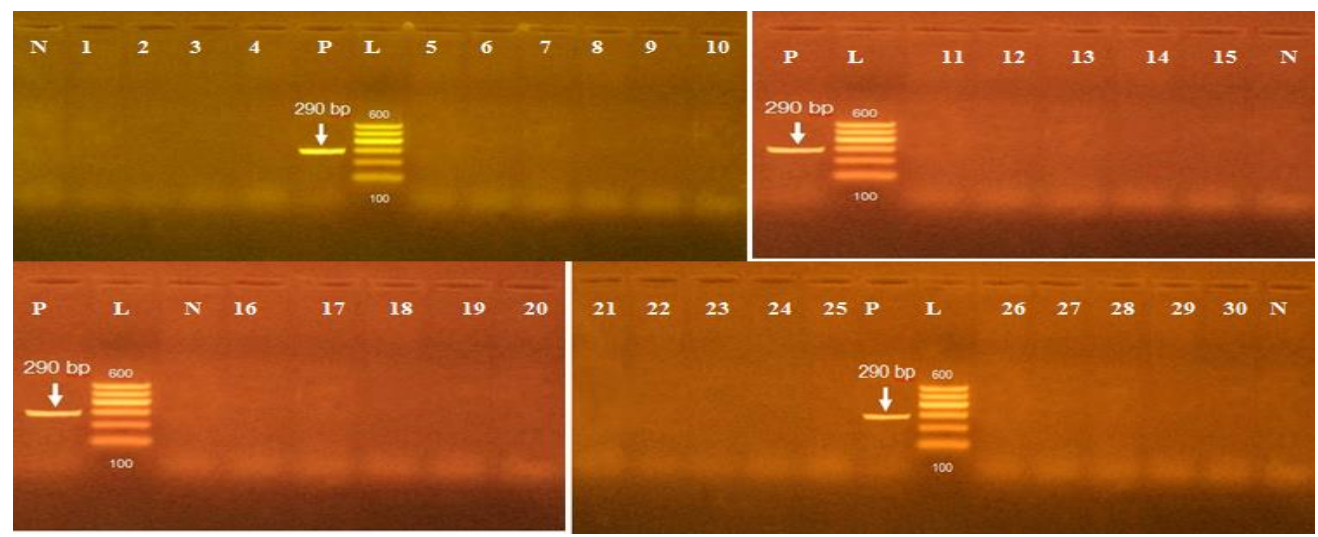

(c)

Fig. 2: PCR results of the examined samples for different meat species; (a) Equine species; The examined samples for different species of meat detected by conventional PCR technique where, lane L: ladder, lane P: positive, lane N: negative, lane 1 to 10: hawawshi samples, lane 11 to 20: sausage samples, lane 21 to 30: burger samples; (b) Chicken Species; The examined samples for different species of meat detected by conventional PCR technique where, lane L: Ladder, lane P: Positive, lane N: Negative, lane 1 to 10: hawawshi samples, lane 11 to 20: sausage samples, lane 21 to 30: burger samples; (c) Pig Species; The examined samples for different species of meat detected by conventional PCR technique where, lane L: ladder, lane P: positive, lane N: negative, lane 1 to 10: hawawshi samples, lane 11 to 20: sausage samples, lane 21 to 30: burger samples 


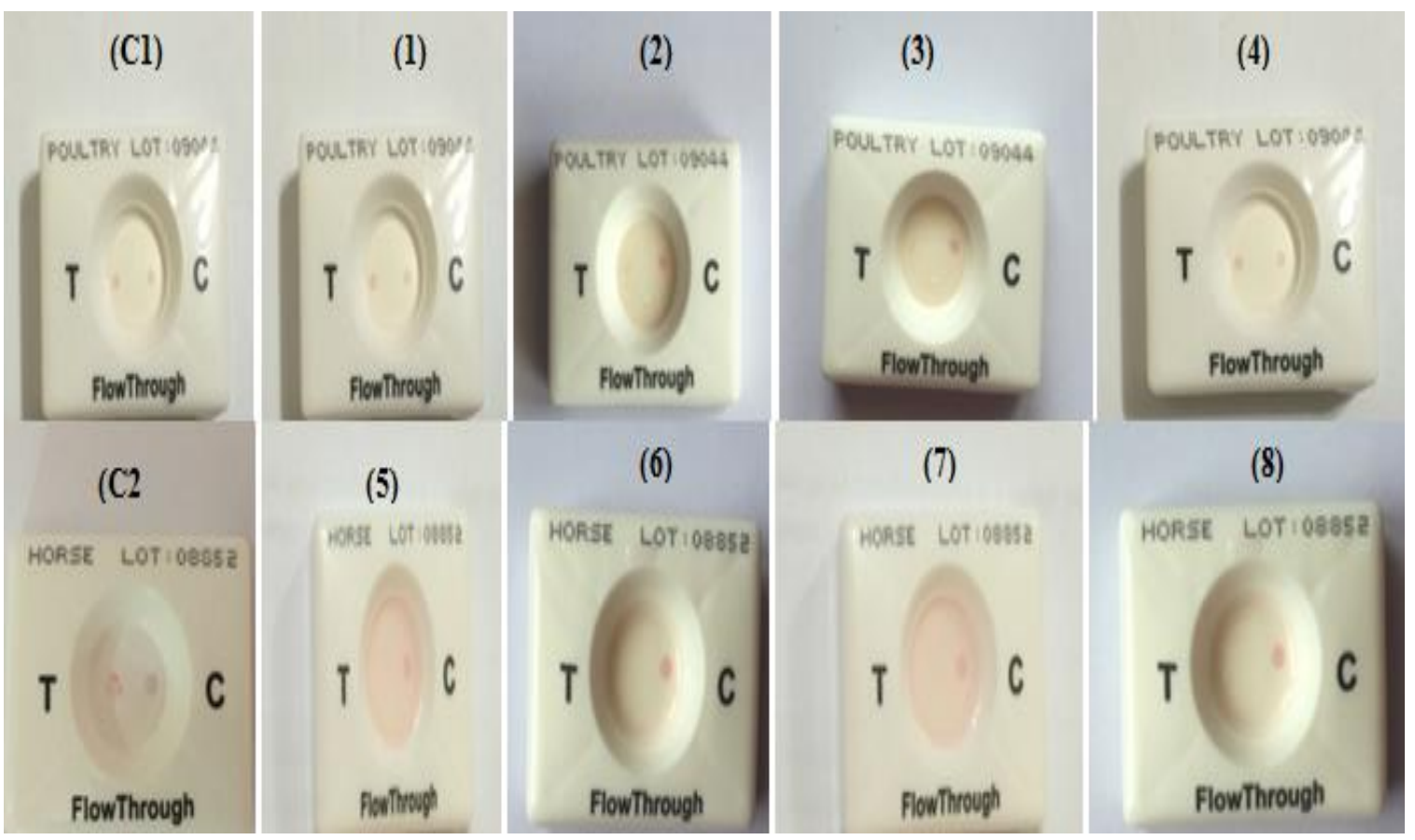

Fig. 3: Incidence of adulteration of meat product samples by equine and chicken species detected by Raw Meat Flowthrough ${ }^{\mathrm{TM}}$ Test

The results presented in Table 5 and Fig. 3 showed that all the samples which were found to be adulterated with chicken by the PCR technique had given positive results which confirmed that they contained poultry meat. While all the samples which were found to be adulterated with equine meat by the PCR technique had given negative results which showed that they contained no horse meat, but this means that the test had not the ability to detect all the equine species and work on horse specie only not included donkey and mule and thus, could be beneficial tool to differentiate between the equine species adulterations and promising opportunity to the developers to develop a new tools for equine as a general species and another one specified for donkeys and mules. Increased precision of the methods used will allow increased trust in the safety of the products in international trade and will provide reliable evidence for the probable court cases (Kesmen et al., 2010).

\section{Conclusion}

The outcome of this study showed that regular controls for adulteration in meat products should be frequently and intensively done due to demonstrating the presence of undeclared meat in products. The PCR technique and RMFT test potentially powerful and reliable techniques for detection of adulteration with different meat species in meat products and they could be useful and applied by researchers and quality control laboratories for verification and control of industrial meat products, to verify the origin of the raw materials. Therefore, they can be suggested as useful laboratory tools for species identification, especially for meat traceability and Halal authentication. Furthermore, these studies are important in other respects such as regaining consumer confidence, reduction of losses due to unfair competition and production deficiencies and increasing the contribution of the sector to the national economy. But the FlowThrough ${ }^{\mathrm{TM}}$ Test had a defect in case of detection of adulteration by equine species, as it can detect horse specie adulteration only but could not detect other equine species as donkey and mule, which consider beneficial in specification the types of adulteration within the equine species.

\section{Acknowledgment}

All author acknowledged the technical support provided by Food Hygiene Department and Poultry disease Department staff members, Faculty of Veterinary Medicine, Suez Canal University.

\section{Author's Contributions}

All authors equally contributed in this work.

\section{Ethics}

The experiment approved by Suez Canal University ethical committee. 


\section{References}

Ahmed, H., M. El-Nasser, D. Mohammed, M. Mohamed and J. Köfer et al., 2011. Identification of meat species in some raw meat products in Assiut city, Egypt. Animal hygiene and sustainable livestock production. Proceedings of the 45th International Congress of the International Society for Animal Hygiene, Jul. 3-7, Vienna, Austria, pp: 973-975.

Ahmed, M.M., S.M. Abdel-Rahman and A.A. El-Hanafy, 2007. Application of species-specific polymerase chain reaction and cytochrome-b gene for different meat species authentication. Biotechnology, 6: 426-430. DOI: $10.3923 /$ biotech.2007.426.430

Ali, A., 2011. Effect of some nutritional additives on the quality and formulation cost of beef burger. Cairo University.

Ayaz, Y., N. Ayaz and I. Erol, 2006. Detection of species in meat and meat products using Enzyme-Linked Immunosorbent Assay. J. Muscle Foods, 17: 214-220. DOI: 10.1111/j.1745-4573.2006.00046.x

Ayoub, M.A., W. Elfeil, D.E. Boraey, H. Hammam and M.A. Nossair, 2019. Evaluation of some vaccination programs in protection of experimentally challenged broiler chicken against Newcastle disease virus. Am. J. Anim. Vet. Sci., 14: 197-206.

DOI: 10.3844/ajavsp.2019.197.206

Ballin, N.Z., F.K. Vogensen and A.H. Karlsson, 2009. Species determination-can we detect and quantify meat adulteration? Meat Sci., 83: 165-174. DOI: 10.1016/j.meatsci.2009.06.003

Bowling, M., K. Belk, K. Nightingale, L. Goodridge and J. Scanga et al., 2007. Central nervous system tissue in meat products: An evaluation of risk, prevention strategies and testing procedures. Adv. Food Nutrit. Res., 53: 39-64. DOI: $10.1016 / \mathrm{S} 1043-4526(07) 53002-0$

Cawthorn, D.M., H.A. Steinman and L.C. Hoffman, 2013. A high incidence of species substitution and mislabelling detected in meat products sold in South Africa. Food Control, 32: 440-449. DOI: 10.1016/j.foodcont.2013.01.008

Diab, M.S., M.S. Abd-ElHafez, M.A. Ashry and W.K. Elfeil, 2019. Occurrence of avian influenza H5N1 among chicken, duck farms and human in Egypt. Am. J. Anim. Vet. Sci., 14: 26-32. DOI: 10.3844/ajavsp.2019.26.32

Doosti, A., P.G. Dehkordi and E. Rahimi, 2014. Molecular assay to fraud identification of meat products. J. Food Sci. Technol., 51: 148-152. DOI: 10.1007/s13197-011-0456-3

Eid, H.I., A.M. Algammal, S.A. Nasef, W.K. Elfeil and G.H. Mansour, 2016. Genetic variation among avian pathogenic E. coli strains isolated from broiler chickens. Asian J. Anim. Vet. Adv., 11: 350-356. DOI: 10.3923/ajava.2016.350.356
Eid, H.M., A.M. Algammal, W.K. Elfeil, F.M. Youssef and S.M. Harb et al., 2019. Prevalence, molecular typing and antimicrobial resistance of bacterial pathogens isolated from ducks. Vet. World, 12: 677-683. DOI: 10.14202/vetworld.2019.677-683

Elfeil, W.K., R.R. Abouelmaatti, C. Sun, W. Han and X. Li et al., 2012. Identification, cloning, expression of a novel functional anasplatyrhynchos mRNA TLR4. J. Anim. Vet. Adv., 11: 1727-1733. DOI: $10.3923 /$ javaa.2012.1727.1733

Elhady, M.A., A. Ali, W.H. Kilany, W.K. Elfeil and H. Ibrahim et al., 2018. Field efficacy of an attenuated infectious bronchitis variant 2 virus vaccine in commercial broiler chickens. Vet. Sci., 5: 49-49. DOI: $10.3390 /$ vetsci5020049

Enany, M.E., A.M. Algammal, A.M. Hanora, G.I. Shagar and W.K. Elfeil et al., 2018. Molecular typing and evaluation of sidr honey inhibitory effect on virulence genes of MRSA strains isolated from catfish in Egypt. Pak. J. Pharmaceutical Sci., 31: 1865-1870.

Fawzy, M., R.R. Ali, W.K. Elfeil, A.A. Saleh and W.H. Mady et al., 2019. Efficacy of inactivated velogenic Newcastle disease virus genotype VII vaccine in broiler chickens. Veterinary Research Forum.

Gaafar, R., 2017. Advanced studies to detect commercial adulteration in meat products at Ismailia markets: Hygiene and Control of Meat, Fish and their Products and Animal By-Products. Suez Canal University.

Ghovvati, S., M. Nassiri, S. Mirhoseini, A.H. Moussavi and A. Javadmanesh, 2009. Fraud identification in industrial meat products by multiplex PCR assay. Food Control, 20: 696-699.

DOI: 10.1016/j.foodcont.2008.09.002

Hsieh, Y.H.P., M.A. Johnson, C.J. Wetzstein and N.R. Green, 1996. Detection of species adulteration in pork products using agar-gel immunodiffusion and enzyme-linked immunosorbent assay. J. Food Quality, 19: 1-13.

DOI: $10.1111 / \mathrm{j} .1745-4557.1996 . t b 00401 . x$

Hussien, S.F.M., 2011. Identification of meat species using recent techniques.

Ilhak, O.I. and A Arslan, 2007. Identification of meat species by Polymerase Chain Reaction (PCR) technique. Turk. J. Vet. Anim. Sci., 31: 159-163.

Ilhak, O.I. and H.Ş. Güran, 2014. Authentication of meat species in Sucuk by multiplex PCR.

Joseph, W., G. Nasinyama, K. Erastus and O. William, 2006. Adulteration of beef sausages with pork sold in supermarkets in Kampala-Uganda. African J. Anim. Biomed. Sci., 1: 41-45.

Kesmen, Z., F. Sahin and H. Yetim, 2007. PCR assay for the identification of animal species in cooked sausages. Meat Sci., 77: 649-653.

DOI: 10.1016/j.meatsci.2007.05.018 
Kesmen, Z., H. Yetim and F. Şahin, 2010. Identification of different meat species used in sucuk production by PCR assay. GIDA, 35: 81-87.

Mafra, I., I.M. Ferreira and M.B.P. Oliveira, 2008. Food authentication by PCR-based methods. Eur. Food Res. Technol., 227: 649-665. DOI: $10.1007 / \mathrm{s} 00217-007-0782-\mathrm{X}$

Mahmod, W.A.A., 2008. Identification of some animal species through examination of fresh and frozen meat.

Mehdizadeh, M., S. Mousavi, M. Rabiei, K. Moradian and S. Eskandari et al., 2014. Detection of chicken meat adulteration in raw hamburger using polymerase chain reaction. J. Food Quality Hazards Control, 1: 36-40. DOI: 10.1016/j.jfca.2014.12.009

Montiel-Sosa, J., E. Ruiz-Pesini, J. Montoya, P. Roncales and M. López-Pérez et al., 2000. Direct and highly species-specific detection of pork meat and fat in meat products by PCR amplification of mitochondrial DNA. J. Agric. Food Chem., 48: 2829-2832. DOI: 10.1021/jf9907438

Rahman, M.M., M.E. Ali, S.B.A. Hamid, S. Mustafa and U. Hashim et al., 2014. Polymerase chain reaction assay targeting cytochrome $b$ gene for the detection of dog meat adulteration in meatball formulation. Meat Sci., 97: 404-409.

DOI: 10.1016/j.meatsci.2014.03.011

Sambrook, J., E. Fritsch and T. Maniatis, 1989. Molecular Cloning: A Laboratory Manual. 1st Edn., John Wiley and Sons, New York, pp: 1120.

Sedeik, M.E., A.M. Awad, H. Rashed and W.K. Elfeil, 2018. Variations in pathogenicity and molecular characterization of Infectious Bursal Disease Virus (IBDV) in Egypt. Am. J. Anim. Vet. Sci., 13: 76-86. DOI: 10.3844/ajavsp.2018.76.86

Sultan, H.A., A. Ali, W.K. El Feil, A.H.I. Bazid and M.A. Zain El-Abideen et al., 2019a. Protective efficacy of different live attenuated infectious bronchitis virus vaccination regimes against challenge with IBV variant-2 circulating in the middle east. Frontiers Vet. Sci., 6: 341-341.

DOI: 10.3389/fvets.2019.00341
Sultan, H.A., A.E. Arafa, S. Talaat, A.A. Gaballa and W.H. Kilany et al., 2019b. Efficacy of clade 2.3.2 H5-recombinant baculovirus vaccine in protecting Muscovy and Pekin ducks from clade 2.3.4.4 H5N8 highly pathogenic avian influenza infection. Avian Dis., 63: 219-229. DOI: 10.1637/11880-042718.1

Tasara, T., S. Schumacher and R. Stephan, 2005. Conventional and real-time PCR-based approaches for molecular detection and quantitation of bovine species material in edible gelatin. J. Food Protect., 68: 2420-2426. DOI: 10.4315/0362-028X-68.11.2420

Unajak, S., P. Meesawat, K. Anyamaneeratch, K. Srikulnath and K. Choowongkomon, 2011. Identification of species (meat and blood samples) using nested-PCR analysis of mitochondrial DNA. African J. Biotechnol., 10: 5670-5670.

Wang, H.C., S.H. Lee, T.J. Chang and M.L. Wong, 2004. Examination of meat components in commercial dog and cat food by using Polymerase Chain Reaction-Restriction Fragment Length Polymorphisms (PCR-RFLPs) technique. J. Vet. Med. Sci., 66: 855-859. DOI: 10.1292/jvms.66.855

Yosef, T., M. Al-Julaifi and A. Al-Rizqi, 2014. Food forensics: Using DNA-based technology for the detection of animal species in meat products. Nature Sci., 12: 82-90.

Zahran, D. and S. Hagag, 2015. Use of molecular biology techniques in the detection of fraud meat in the Egyptian market. Afr. J. Biotechnol., 14: 360-364. DOI: 10.5897/AJB2014.14297

Zarringhabaie, G.E., N. Pirany and A. Javanmard, 2011. Molecular traceability of the species origin of meats using multiplex PCR. Afr. J. Biotechnol., 10: 16461-16465. DOI: $10.5897 / A J B 11.1250$ 